\title{
Учет региональных особенностей в формировании образовательных программ по туризму и гостеприимству в Алтайском крае
}

\author{
Биттер Н.В. \\ Алтайский государственный технический университет им. И.И. Ползунова, \\ Россия, 656038, г. Барнаул пр-т Ленина, 46 \\ E-mail: valeolog@yandex.ru
}

\begin{abstract}
Аннотация. В настоящее время недостаточно проработан региональный компонент образовательных программ по туризму и гостеприимству, не разработаны в полной мере региональные профессиональные компетенции специалистов в сфере туризма. В связи с этим автором проанализированы образовательные программы по туризму и гостеприимству в Алтайском крае и их наполнение, а также раскрыто влияние рекреационных особенностей и культурно-исторического развития Алтайского края на наполнение образовательных программ в данной отрасли. Проведен анализ и обобщение методологического опыта и сравнения систем формирования образовательных программ по туризму и гостеприимству в России и за рубежом. Рассмотрены исторические этапы становления системы подготовки кадров в сфере туризма и гостеприимства в России и Алтайском крае. Учет региональных рекреационных особенностей Алтайского края при развитии сферы туризма и гостеприимства должен являться ключевым фактором, определяющим изменение требований к выпускникам данного направления и, как следствие, к организации процесса формирования образовательных программ. Полученные результаты могут быть интересны исследователям, занимающимся сравнением педагогических систем подготовки кадров туризма и гостеприимства, работникам данных сфер, широкому кругу читателей, интересующихся вопросами подготовки кадров сфер туризма и гостеприимства.
\end{abstract}

Ключевые слова: подготовка кадров в туризме, формирование образовательных программ, региональная туристская отрасль.

Для цитирования: Биттер Н.В. 2020. Учет региональных особенностей в формировании образовательных программ по туризму и гостеприимству в Алтайском крае. Вопросы журналистики, педагогики, языкознания, 39 (2): 197-205. DOI 10.18413/2712-7451-2020-39-2-197-205

\section{Consideration of regional features in the formation of educational programs in tourism and hospitality in Altai krai}

\author{
Natalia V. Bitter \\ Polzunov Altai State Technical University, \\ 46 Lenina prospekt, Barnaul, 656038, Russia \\ E-mail: valeolog@yandex.ru
}

\begin{abstract}
At the present stage of tourism development in Altai Krai and the increase in the tourist flow the formation of tourism educational programs taking into account regional peculiarities of the region is relevant. Currently the regional component of educational programs on tourism and hospitality is not sufficiently formulated, and regional professional competencies of graduates in this field of activity are
\end{abstract}


not fully developed. In this regard, in order to evaluate the current state of tourism and hospitality educational programs formation in Altai Krai, the author analyzed their content and revealed the impact of recreational features and cultural and historical development of Altai Krai on the educational programs content in this industry. The analysis and generalization of methodological experience and comparison of tourism and hospitality educational programs formation systems in Russia and abroad were carried out. The historical stages of the personnel training system formation for tourism and hospitality in Russia and Altai Krai were considered. Consideration of the regional recreational features of Altai Krai in ttourism and hospitality development should be a key factor in determining the change in the requirements for graduates of this direction and, consequently, the peculiarities of the educational programs formation process organization. The results obtained may be of interest to the researchers involved in comparing tourism and hospitality training pedagogical systems, to employees, to a wide range of readers interested in the issues of tourism and hospitality training.

Keywords: tourism training, educational programs formation, regional tourism industry.

For citation: Bitter N.V. 2020. Consideration of regional features in the formation of educational programs in tourism and hospitality in Altai krai. Issues in Journalism, Education, Linguistics, 39 (2): 197205. (in Russian). DOI 10.18413/2712-7451-2020-39-2-197-205

\section{Введение}

Современная система образования, экономические условия предъявляют все большие требования к качеству процесса подготовки кадров для индустрии туризма и гостеприимства. Подготовка в сфере туризма и гостеприимства в России и за рубежом охватывает все составляющие данной сферы: гостеприимство, туризм, ресторанное и гостиничное дело, а также менеджмент, администрирование. А.Н. Морозова [2008] отмечает, что мировая система подготовки кадров для сферы туризма начала формироваться в конце XIX - начале XX в.

В настоящее время подготовка кадров для индустрии туризма и гостеприимства в мире осуществляется по большому количеству образовательных программ. К сожалению, данные программы зачастую носят ознакомительный характер со спецификой туристской деятельности. Дисциплины, представленные в образовательных программах, не в полной мере отражают их туристское содержание. С другой стороны, иногда дисциплины и модули, которые имеют в названиях слово «туризм», используют прикладной материал по туризму поверхностно или однобоко [Gallarza, Gil, 2008]. Мы видим, что часто в данных программах не учитывают региональные особенности региона, где ведется подготовка кадров для сфер туризма и гостеприимства.

Среди регионов Сибирского федерального округа Алтайский край является лидером по развитию туризма и гостеприимства. Это оказывает прямое влияние на востребованность квалифицированных кадров данной сферы. К выпускникам предъявляются требования владения не только профессиональными, но также и региональными компетенциями. Данные компетенции формируются в процессе изучения природных комплексов, рекреационных особенностей Алтайского края.

Отметим, что на систему подготовки кадров для индустрии туризма и гостеприимства и формирование образовательных программ в Алтайском крае прямое влияние оказывает специфика развития туристской отрасли.

Целью данной статьи является проведение сравнительного педагогического обзора системы подготовки кадров для индустрии туризма и гостеприимства в зарубежной и отечественной педагогике, а также анализ программ по подготовки кадров для индустрии туризма в Алтайском крае и региональных особенностей развития туризма. 
Для достижения поставленной цели был проведен теоретический анализ программ подготовки кадров для индустрии туризма в России и за рубежом, изучен и обобщен практический педагогический опыт по исследуемому вопросу. В процессе работы над статьей использован системно-структурный анализ, системный подход.

\section{Система подготовки кадров для индустрии туризма за рубежом}

Становление системы подготовки кадров для индустрии туризма берет свое начало в Европе. В это время в европейском образовании происходили интеграционные процессы, начатые с целью создания и развития системы высшего профессионального образования, позволяющей будущим студентам свободно выбирать учебные заведения, работу, сферу деятельности и страны, в которых они смогут получить образование. В 1893 г. в Швейцарии местной ассоциацией отельеров были созданы образовательные учреждения по подготовке кадров в сфере сервиса и туризма. [Sandro Formica, 1996].

В это же время в США начинает осуществляться двухнедельная переподготовка и повышение квалификации по туризму. К 60-м гг XX в. началось обучение специалистов по туризму на базе университетов и колледжей [Sandro Formica, 1996].

Подготовка кадров для туристской индустрии во Франции в настоящее время происходит по двум видам: короткая и длинная профессиональная подготовка. Образовательные программы в области туристской и гостиничной сферы реализуются по двум направлениям на уровне дипломов BTS:

- продажа турпродукта (для турагентств) - этот диплом признан лучшим европейским дипломом по продаже турпродукта;

- развитие туризма на уровне территорий (работа в туристских администрациях, офисах по туризму и пр.) [Ермилова, 2014].

Наиболее известной и востребованной системой подготовки кадров для индустрии туризма и гостеприимства является система образования по туризму и гостиничному делу в Швейцарии, являющаяся эталоном в сфере Hotel Management \& Tourism. В Швейцарии имеется множество школ гостиничного и туристского менеджмента, которые являются частными. Необходимо отметить, что зачастую профессиональные ассоциации открывают собственные школы туризма и гостиничного дела [Ермилова, 2000].

Известные образовательные учреждения располагаются в Барселоне. Одним из известных образовательных учреждений является Escola Universitariade Turisme Barcelona, основанное в 1987 году. В данном образовательном учреждении применяют новейшие технологии и современные образовательные методики. В школе происходит обучение по четырем профессиональным программам. Обучение по программе Grado Superiorde Agenciasde Viajes позволяет выпускнику после окончания учебного заведения получить работу в отрасли туристского бизнеса и гостеприимства [WTO, 2010].

Таким образом, рассмотрев и проанализировав становление системы подготовки кадров для сферы туризма за рубежом, отметим, что профессиональная подготовка в сфере туризма за рубежом имеет ряд особенностей и преимуществ:

- наличие многоуровневой системы образования в сфере туризма, согласованность и преемственность всех ступеней профессионального образования, определение выходной квалификации каждого уровня;

- образовательные программы разрабатываются с учетом требований профессиональных квалификационных стандартов;

- существует возможность получения непрерывного образования, а также прохождения переподготовки в течение всей профессиональной карьеры; 
- подготовка специалистов осуществляется с учетом требований европейских образовательных стандартов и квалификаторов с целью формирования единых требований при трудоустройстве;

- практикоориентированное обучение студентов туристских специальностей;

- формирование мотивации студентов к будущей профессиональной деятельности;

- формирования профессиональных и общекультурных компетенций при работе с клиентами с самого начала обучения;

- образовательный процесс осуществляется во взаимодействии образовательных учреждений с предприятиями сферы туризма, гостеприимства и национальными профессиональными организациями. Результатом данного взаимодействия является организация и проведение профессиональных практик, консультирование по содержанию подготовки, разработка учебных планов и программ с учетом требований работодателей;

- развитая материальная инфраструктура образовательных заведений, обеспечивающая базу для проведения занятий и практик.

\section{Отечественный опыт подготовки кадров для туристской индустрии}

Образование в сфере туризма в отечественной педагогике начало развиваться намного позже, чем в зарубежной педагогике. Рассматривая исторический аспект становления образования в сфере туризма в отечественной педагогике, отметим, что в середине XIX столетия начала развиваться система подготовки кадров для экскурсионного образовательного туризма, который в дальнейшем стал отправной точкой для зарождения образования туристской индустрии в России. Ялтинское отделение Крымского горного клуба начало первым в России (в 1902 году) проводить курсовую подготовку кадров. Со временем экскурсионная практика стала развиваться, и в 10-е годы в некоторых городах России в школах открылись кратковременные экскурсионные курсы [Базаров, 2005].

Следующим витком в развитии образования в сфере туризма является просветительская деятельность В.И. Верещагина в области экскурсионного дела на Алтае. Первым научным изданием в данной сфере являются методические рекомендации Виктора Ивановича Верещагина «Алтай, как район ученических экскурсий» (1910 г.).

Изучение истории данного вопроса позволяет отметить, что 20-е гг. ХХ в. характеризуются началом становления системы профессионального образования. Связано это с тем, что в данный период времени в мире начинает формироваться туристская индустрия, сопровождающаяся активной подготовкой профессиональных кадров по туризму.

На наш взгляд, следующим этапом в подготовке кадров для индустрии туризма являются 50-е годы XX века. В этот период началось преподавание туристских дисциплин на факультетах физического воспитания педагогических институтов. В Алтайском регионе данная подготовка осуществлялась в педагогическом институте города Горно-Алтайска. Е.А. Кондратенко [2008] в своей диссертации отмечает, что расширение курсовой подготовки по экскурсиям осуществлялось Центральным советом по туризму и экскурсиям.

Отметим, что политика подготовки кадров в 1970-е годы в Западной Сибири в туристской сфере была в основном направлена на подготовку специалистов туристскоэкскурсионного направления. Осуществлялось повышение методологического уровня будущих специалистов экскурсионной работы. 


\section{Современное состояние туристского образования в Алтайском крае с учетом региональных особенностей}

В настоящее время специалисты в сфере туризма востребованы на рынке труда, особенно в Алтайском крае, который позиционирует себя как уникальная зона туристического отдыха. Поэтому одна из приоритетных задач, которая стоит перед региональными вузами - это подготовка квалифицированных кадров.

Начиная с 90-х гг. XX в. на формирование образовательных программ подготовки кадров для индустрии туризма оказывает влияние развитие туризма в Алтайском крае как многопрофильного туристского региона в контексте множества видов туризма: лечебнооздоровительного, сельского, экологического, научно-познавательного, экстремального, событийного, делового. Развитие отрасли туризма в крае оказало влияние на потребность в высококвалифицированных специалиста, подготовку которых успешно осуществляет ряд высших и средних учебных заведений Алтайского края.

Подготовка кадров высшего звена для данной сферы начала осуществляться в ФГБОУ ВО «Алтайский государственный технический университет им И.И. Ползунова» (АлтГТУ) в 1998 г. Первые выпускники обучались специальности «Социальнокультурный сервис и туризм» по специализациям «Туризм» и «Курортное дело». Выбор данных направлений подготовки был обусловлен востребованностью специалистов на рынке туристских и санаторных услуг.

В 2009 г. АлтГТУ им. И.И. Ползунова принял участие в работе по реализации гранта международной программы Темпус (Европейская Комиссия) проекта «Международная магистерская программа по туризму для сибирских регионов». Результатом реализации явилось открытие магистерской программы по туризму в 2010 г. В данной магистерской программе осуществлялась трансляция зарубежного опыта подготовки по туризму. Реализация программы носила выраженный практико-ориентированный характер с опорой на региональные особенности Алтайского края.

15 октября 2012 г. Алтайский государственный технический университет вошел в состав партнеров-участников проекта российских и европейских университетов «Tourism lifelong learning network.: сеть региональных центров по туризму» (проект Темпус № 53750-TEMPUS-1-2012-1DK-TEMPUS-JPHES). Результатом данного сотрудничества стало создание в 2016 г. Ресурсного научно-образовательного центра «Темпус». За период своей деятельности данный центр реализовал программу «Школа экскурсоводов» в 2016 г. [Визиталтай.рф, 2015]

В 2016 г. в Алтайском государственном техническом университете им. И.И. Ползунова проводились курсы для специалистов сферы туризма и гостеприимства. При разработке данной программы был учтен европейский опыт подготовки кадров в сфере туризма. Повышение квалификации прошли 52 человека [Мошкин и др., 2016].

В 2015 г. Алтайский край стал пилотной площадкой по реализации федерального проекта по подготовке кадров для туротрасли. Данная программа была направлена на повышение квалификации работников туриндустрии и поддержание конкурентоспособного качества оказания туристских услуг в условиях растущего внутреннего туристского потока. Проект реализовывался совместно с учреждениями высшего профессионального образования в сфере туризма посредством создания местных площадок для обучения дополнительного числа специалистов по учебным программам, представленным Ростуризмом. В него вошли 5 вузов, готовящих специалистов в сфере туризма (начиная с контактного персонала и заканчивая уровнем высшего менеджмента), а также КГБПОУ «Алтайская академия гостеприимства». 
В рамках краевой программы содействия занятости населения востребованные профессии в туристском бизнесе (или повышение квалификации) могут получить клиенты центров занятости населения. С 2009 г. безработным гражданам оказывается финансовая поддержка по открытию собственного дела, в том числе и в сфере туризма [Официальный сайт Алтайского края, 2016]. Данная программа была продолжена в 2016 г. В том же году курсы повышения квалификации по дистанционной форме обучения за счет средств федерального бюджета успешно окончили около 80 слушателей Алтайского края.

Кроме того, Алтайский государственный университет в 2016 г. стал региональной образовательной площадкой данного проекта. Вузом были организованы и проведены курсы (очная форма обучения) по различным программам. Обучение прошел 21 представитель турбизнеса Алтайского края.

Алтайский государственный педагогический университет в 2016 г. получил наградной сертификат от организаторов проекта за активную работу в качестве региональной образовательной площадки прошедшего года. В сентябре 2016 года два представителя вуза прошли обучение в Республике Кипр, являющейся зарубежной образовательной площадкой проекта. Федеральным агентством по туризму совместно с Государственным университетом управления (г. Москва) в рамках федеральной целевой программы «Развитие внутреннего и въездного туризма в Российской Федерации (20112018 гг.)» проекта «Общенациональная система подготовки и повышения квалификации специалистов индустрии туризма».

Следует отметить, что в настоящее время высшие учебные заведения Алтайского края значительно продвинулись в подготовке кадров для туристской отрасли. Сегодня вузы готовят специалистов по различным направлениям как бакалавриата, так и магистратуры: «Туризм», «Гостиничное дело» «Сервис». Подготовка осуществляется по следующим профилям: «Технология и организация туроператорских и турагентских услуг; «Туризм и туристские рынки: глобальный, региональный, национальный»; «Современные методы и технологии социокультурного сервиса»; «Технология и организация экскурсионных услуг»; «Управление туристскими организациями»; «Гид-переводчик в туриндустрии».

Подготовку специалистов среднего и начального звена для индустрии туризма и гостеприимства осуществляют колледжи, лицеи и вузы на специализированных курсах. Ведущим образовательным учреждением в данной сфере является КГБПОУ «Алтайская академия гостеприимства».

Рост востребованности специалистов данной отрасли связан с тем, что развитие сферы туризма, реализация на территории края крупных инвестиционных проектов в сфере туризма, по экспертной оценке, потребуют дополнительного привлечения более 8 тыс. человек. Отметим, в рамках Стратегии социально-экономического развития Алтайского края на период до 2025 г. туризм признан в числе приоритетных направлений в экономике региона. Все это напрямую влияет на формирование образовательных программ «Туризм», «Сервис», «Гостиничное дело». Необходимы специалисты по экскурсионному делу, санаторно-курортной и гостиничной сферам. Наблюдается нехватка специалистов среднего звена, владеющих компетенциями в сфере туризма и гостеприимства и обладающих необходимыми знаниями специфики туристской отрасли Алтайского края.

В настоящее время к работникам туристской сферы предъявляются все большие требования. Так, Ю.П. Мухамадиева [2017] указывает, что специалист, работающий в туристской сфере, помимо владения профессиональными и общекультурными компетенциями, должен иметь практический опыт, постоянно повышать свою профессиональную квалификацию. Вместе с тем О.Г. Павлов [2013] делает акцент на том, что разработчики современных программ должны стремиться формировать учебные планы по туризму и 
гостеприимству по диагонали нескольких секторов туристской индустрии, которые в дальнейшем помогут выпускникам в карьерном росте.

Формирование образовательных программ по туризму и гостеприимству, должно осуществлять с учетом региональной специфики того региона, где осуществляется образовательная деятельность, в частности Алтайского края. Данное обстоятельство обусловлено тем, что большинство выпускников остаются работать в Алтайском регионе, что требует формирование региональных компетенций.

Необходимо формирование горизонтальной и вертикальной систем управления в данной сфере. В современных условиях наиболее эффективным является применение системного подхода при формировании образовательных программ, учитывающих и рекреационные особенности Алтайского края, а также зарубежного опыта выстраивания систем подготовки кадров для индустрии туризма. Формирование образовательных программ необходимо осуществлять также с учетом развития различных видов туризма, наиболее востребованных в Алтайском регионе на современном этапе: лечебно-оздоровительного, культурно-познавательного, активного, культурно-исторического.

\section{Заключение}

Бурное развитие отрасли туризма в Алтайском крае предъявляет все более жесткие требования к подготовке кадров для данной сферы. Несмотря на то, что в настоящее время имеется достаточное количество образовательных учреждений, которые способны удовлетворить этот спрос, вопрос квалифицированных кадров остается актуальным.

Региональная специфика туризма в крае оказывает влияние на отсутствие спроса на специалистов широкого профиля. В настоящее время наиболее востребованы специалисты, обладающие региональными компетенциями, а не только общими профессиональными компетенциями. От выпускников вузов и сузов требуются знания в конкретных областях туризма и гостеприимства края. В этой связи обучение будущих специалистов области туризма и гостеприимства должно осуществляться по конкретным региональным профилям подготовки будущих специалистов.

При разработке программ различных профилей подготовки необходимо вводить в учебный план дисциплины, изучающие специфику туристской индустрии Алтайского края: туристское краеведение, региональные гостинично-туристские и санаторнокурортные комплексы, региональное гостиничное и туристское хозяйство, региональный опыт санаторно-курортной и туристской сферы и т.п. Включение в учебный план данных дисциплин, а также проведение практических занятий на предприятиях индустрии гостеприимства и туризма Алтайского края позволят сформировать необходимый уровень практических знаний и навыков, максимально приблизить к потребностям работодателей. Также это будет способствовать развитию у студентов мобильности, эрудированности, коммуникабельности, умения продвигать региональный туристский продукт на федеральный и международный туристский рынок.

Итак, мы видим, что в настоящее время остро стоит вопрос подготовки специалистов для сферы туризма, осуществляемый с учетом региональных рекреационных особенностей Алтайского края. Отметим, что формирование образовательных программ для данной отрасли в Алтайском крае на основе рекреационного и исторического подхода требует учета рекреационных особенностей и культурно-исторического развития Алтайского края.

\section{Список источников}

1. Базаров Т.Ю. 2005 Управление персоналом. М., ИНФРА-М, 560 с.

2. Визиталтай.рф Барнаул, 2015. URL: http://www.visitaltai.info/more_categories/news/6699/ (дата обращения: 25.02.2020). 
3. Готовить кадры для туротрасли будут в Алтайском крае. 2015. Алтайский край. Клуб регионов. URL: http://club-rf.ru/22/news/38262 (дата обращения: 03.02.2020).

4. В Алтайском крае увеличивается потребность в кадрах для туристической отрасли. 2016. Официальный сайт Алтайского края. URL: https://www.altairegion22.ru/region_news/valtaiskom-krae-uvelichivaetsya-potrebnost-v-kadrah-dlya-turisticheskoiotrasli_473576.html?sphrase_id=988834 (дата обращения: 03.02.2020).

\section{Список литературы}

1. Ермилова Д.В. 2014. Обзор современного высшего образования в сфере туризма за рубежом. Вестник РМАТ, 4: 78-88.

2. Ермилова Д. В. 2000. Теория и методика высшего туристского образования в европейских странах. Дис. ... канд. пед. наук. Сходня, Моск. обл. 177 с.

3. Кондратенко Е.А. 2008. Состояние и развитие туристско-экскурсионной отрасли Западной Сибири в 1970-е годы. Автореф. дис. ... канд. истор. наук. Омск, 21 с.

4. Морозова Н.С. 2008. Международный опыт подготовки кадров для туристской индустрии. Вестник национальной академии туризма, 4(8): 74-76.

5. Мошкин В.Н., Биттер Н.В., Шаховалов Н.Н., Шаховалова Е.Г. 2016. Роль повышения квалификации в профессиональном развитии специалистов в сфере туризма. Научный результат. Педагогика и психология образования, 2 (4): 18-22. DOI: 10.18413/2313-8971-2016-2-4-18-22.

6. Мухамадиева Ю.П., Полупанов И.И. 2017. Актуальные проблемы кадрового обеспечения в сфере туризма. Молодой ученый, 13.2 (147.2): 15-17. URL: https://moluch.ru/archive/147/42016/ (дата обращения: 01.02.2020).

7. Павлов О.Г. 2013. Зарубежный опыт подготовки кадров для туризма. Среднее профессиональное образование, 11: 54-55.

8. Солодовникова Ю.Р. 2010. Проблема подготовки кадров в сфере туризма в ЗападноСибирском регионе: историографический аспект. Омский научный вестник-5 (91): 23-27.

9. Association for Tourism and Leisure Education. URL: http://www.atlas-euro.org/ (дата обращения: 20.02.2020).

10. Gallarza M.G., Gil I. 2008. The concept of value and its dimensions: A tool for analyzing tourism experiences. Tourism Review, 63 (3): 4-20

11. Morey A. 2000. Changing higher education curricula for a global and multicultural worl. Higher education in Europe, April (1): 25-41.

12. Sandro Formica. 1996. European hospitality and tourism education: Differ-ences with the American model and future trends. Journal Hospitality Management, 15.4: 317-323.

13. World Tourism Organization (WTO). 2000. Educating the Educators in Tourism. Instituto de Turismo, Empresa y Sociedad y Universidad Politecnica de Valencia. Madrid: WTO: 34-45.

14. WTO. 2010. TNS Global Survey., September. Available at: http://www.world-tourism.org. (дата обращения: 20.02.2020).

\section{References}

1. Ermilova D.V. 2014. World Tourism and Hospitality Schools Overview. Vestnik RIAT Rmat Bulletin, 4: 78-88. (In Russian).

2. Ermilova D.V. 2000. Teorija i metodika vysshego turistskogo obrazovanija v evropejskih stranah [Theory and Methodology of Higher Education in Tourism in European Countries]. Dis. ... cand. ped. sciences. Shodnya, Mosc. obl. 177 p.

3. Kondratenko E.A. 2008. Sostojanie i razvitie turistsko-ekskursionnoj otrasli Zapadnoj Sibiri v 1970-e gody [State and Development of Tourist and Excursion Industry in West Siberia in the 1970s]. Abstract. dis. ... cand. hist. sciences. Omsk, 21 p.

4. Morozva N.S. 2008. Mezhdunarodnyy opyt podgotovki kadrov dlya turistskoy industrii [International experience in training personnel for the tourism industry]. Vestnik natsional'noy akademii turizma, 4(8): 74-76. 
5. Moshkin V.N., Bitter N.V., Shahovalov N.N., Shahovalova E.G. 2016. The role of advanced training in the professional development of specialists in tourism. Research Result. Pedagogy and Psychology of Education, 2 (4): 18-22. DOI: 10.18413/2313-8971-2016-2-4-18-22. (In Russian).

6. Muhamadieva Yu.P., Polupanov I.I. 2017. Aktual'nye problemy kadrovogo obespechenija v sfereturizma. [Actual Problems of Staffing in Tourism Sector]. Molodoy Uchiony, 13.2 (147.2): 15-17. Available at: https://moluch.ru/archive/147/42016/ (accessed: 01.02.2020).

7. Pavlov O.G. 2013. Zarubezhnyj opyt podgotovki kadrov dlja turizma [Foreign experience in training personnel for tourism]. Secondary vocational education, 11: 54-55.

8. Solodovnikova Yu.R. 2010. Problema podgotovki kadrov v sfere turizma v ZapadnoSibirskom regione: istoriograficheskij aspekt [The problem of training in tourism in the West Siberian region: the historiographical aspect]. Omskiy nauchnyy vestnik, 5 (91): 23-27.

9. Association for Tourism and Leisure Education. URL: http://www.atlas-euro.org/ (accessed: 20.02.2020).

10. Gallarza M.G., Gil I. 2008. The concept of value and its dimensions: A tool for analyzing tourism experiences. Tourism Review, 63 (3): 4-20

11. Morey A. 2000. Changing higher education curricula for a global and multicultural worl. Higher education in Europe, April (1): 25-41.

12. Sandro Formica. 1996. European hospitality and tourism education: Differ-ences with the American model and future trends. Journal Hospitality Management, 15.4: 317-323.

13. World Tourism Organization (WTO). 2000. Educating the Educators in Tourism. Instituto de Turismo, Empresa y Sociedad y Universidad Politecnica de Valencia. Madrid: WTO: 34-45.

14. WTO. 2010. TNS Global Survey, September. Available at: http://www.world-tourism.org. (accessed: 20.02.2020).

\section{ИНФОРМАЦИЯ ОБ АВТОРЕ}

Биттер Наталья Викторовна, кандидат педагогических наук, доцент, доцент кафедры менеджмента, заместитель декана гуманитарного факультета Алтайского государственного технического университета им. И.И. Ползунова, г. Барнаул, Россия

\section{INFORMATION ABOUT THE AUTHOR}

Natalia V. Bitter, candidate of pedagogical Sciences, associate Professor, associate Professor of the Department of management, Deputy Dean of the faculty of Humanities, Altai state technical University named after I. I. Polzunov, Barnaul, Russia 